\title{
Upfront Cranial Radiotherapy Followed by Erlotinib Positively Affects Clinical Outcomes of Epidermal Growth Factor Receptor-mutant Non-small Cell Lung Cancer With Brain Metastases
}

\author{
KOICHI SARUWATARI ${ }^{1}$, TOKUNORI IKEDA ${ }^{2}$, SHO SAEKI $^{1}$, NAOKI SHINGU ${ }^{3}$, KOSUKE IMAMURA $^{4}$, \\ TAIYOU KOMATU ${ }^{5}$, SUNAO USHIJIMA ${ }^{6}$, HIROTAKA MARUYAMA $^{7}$, KOSUKE KASHIWABARA ${ }^{8}$, \\ YUSUKE TOMITA $^{1}$, HIDENORI ICHIYASU ${ }^{1}$, KAZUHIKO FUJII $^{1}$ and TAKURO SAKAGAMI ${ }^{1}$ \\ ${ }^{1}$ Department of Respiratory Medicine, Kumamoto University Hospital, Kumamoto, Japan; \\ ${ }^{2}$ Department of Clinical Investigation, Kumamoto University Hospital, Kumamoto, Japan; \\ ${ }^{3}$ Division of Respiratory Medicine, Saiseikai Kumamoto Hospital, Kumamoto, Japan; \\ ${ }^{4}$ Department of Respiratory Medicine, Kumamoto Red Cross Hospital, Kumamoto, Japan; \\ ${ }^{5}$ Department of Respiratory Medicine, NHO Kumamoto Saishunso Hospital, Kumamoto, Japan; \\ ${ }^{6}$ Department of Respiratory Medicine, Kumamoto Chuo Hospital, Kumamoto, Japan; \\ ${ }^{7}$ Department of Respiratory Medicine, Japan Organization of Occupational Health and Safety, \\ Kumamoto Rosai Hospital, Kumamoto, Japan; \\ ${ }^{8}$ Department of Respiratory Medicine, Kumamoto Regional Medical Center, Kumamoto, Japan
}

\begin{abstract}
Background/Aim: The optimal treatment strategy for epidermal growth factor receptor (EGFR)-mutant nonsmall cell lung cancer (NSCLC) patients with brain metastasis (BM) has not yet been fully determined. The aim of this study was to investigate the optimal management of EGFR-mutant NSCLC patients with BM. Patients and Methods: A multicenter retrospective study was performed on the clinical outcomes of 81 advanced/recurrent EGFR-mutant NSCLC patients with BM treated with EGFR-tyrosine kinase inhibitors (EGFR-TKIs) (gefitinib $n=52$ or erlotinib $n=29$ ). Results: Among the 81 patients, 30 patients received upfront cranial radiotherapy $(C R T)$ and 51 did not. The multivariate cox analyses revealed that the use of erlotinib and upfront CRT were independent predictive factors for overall survival (OS) (erlotinib: HR 0.21; 95\% CI, 0.10-0.48; $p<0.001$; upfront CRT: HR 0.42; 95\% CI, 0.20-0.88; $p=0.022$ ). Conclusion: Erlotinib and upfront CRT were associated with
\end{abstract}

This article is freely accessible online.

Correspondence to: Koichi Saruwatari, Department of Respiratory Medicine, Kumamoto University Hospital, 1-1-1, Honjo, Chuo-ku, Kumamoto 860-8556, Japan. E-mail: ksaruwat@kuh.kumamotou.ac.jp

Key Words: Non-small cell lung cancer, brain metastasis, EGFR mutations, gefitinib, erlotinib. a favorable prognosis among EGFR-mutant NSCLC patients with BM. Upfront CRT followed by erlotinib may be an appropriate initial management approach for EGFR-mutant NSCLC patients with BM.

The frequency of brain metastases (BMs) in patients with cancer is approximately $8.5-9.6 \%$, and lung cancer is the most common type of primary tumor responsible for BM (1, 2 ). In non-small cell lung cancer (NSCLC), 40-50\% of patients develop BM during the course of their disease (3). The prognosis of NSCLC patients with BM is poor, with a median survival time of two months without treatment, between four and nine months with chemotherapy, and only seven months with whole-brain radiation therapy (WBRT) (3). Thus, therapeutic developments for these patients are necessary to improve their clinical outcome.

In 2004, epidermal growth factor receptor (EGFR) mutations were discovered in NSCLC and were shown to be correlated with the response to EGFR-tyrosine kinase inhibitors (EGFR-TKI) for NSCLC (4, 5). In several randomized phase III studies of advanced EGFR-mutant NSCLC patients, EGFR-TKIs showed improvements in survival and quality of life compared to patients treated with chemotherapy only (6-9). Consequently, EGFR-TKIs have become the standard treatment for advanced NSCLC patients with EGFR mutations.

In several retrospective analyses, the frequencies of BMs in EGFR-mutant NSCLC patients (64.7-70.3\%) have been 
Table I. Patient characteristics.

\begin{tabular}{|c|c|c|c|c|c|c|c|}
\hline \multirow[t]{2}{*}{ Characteristics } & \multicolumn{2}{|c|}{ All patients } & \multicolumn{2}{|c|}{ Gefitinib } & \multicolumn{2}{|c|}{ Erlotinib } & \multirow[b]{2}{*}{$p$-Value } \\
\hline & $\mathrm{N}=81$ & $(\%)$ & $\mathrm{N}=52$ & $(\%)$ & $\mathrm{N}=29$ & $(\%)$ & \\
\hline \multicolumn{7}{|l|}{ Age, years, median } & 0.223 \\
\hline \multicolumn{8}{|l|}{ Gender } \\
\hline Male & 23 & (28) & 14 & (73) & 9 & (31) & \multirow[t]{2}{*}{0.798} \\
\hline Female & 58 & (72) & 38 & (27) & 20 & (69) & \\
\hline \multicolumn{8}{|l|}{ Smoking } \\
\hline No & 57 & (70) & 36 & (69) & 21 & (72) & \multirow[t]{2}{*}{0.805} \\
\hline Yes & 24 & (30) & 16 & (31) & 8 & (28) & \\
\hline \multicolumn{8}{|l|}{ PS } \\
\hline $0-1$ & 58 & (72) & 37 & (71) & 21 & (72) & \multirow[t]{2}{*}{1.000} \\
\hline$\geq 2$ & 23 & (28) & 15 & (29) & 8 & (28) & \\
\hline \multicolumn{8}{|l|}{ Histology } \\
\hline Adeno & 79 & (98) & 50 & (96) & 29 & $(100)$ & \multirow[t]{2}{*}{0.535} \\
\hline Others & 2 & (2) & 2 & (4) & 0 & (0) & \\
\hline \multicolumn{8}{|l|}{$E G F R$ mutation } \\
\hline Del19 & 33 & (41) & 19 & (37) & 14 & (48) & \multirow[t]{2}{*}{0.350} \\
\hline L858R & 48 & (59) & 33 & (63) & 15 & (52) & \\
\hline \multicolumn{8}{|l|}{ Stage } \\
\hline IV & 77 & (95) & 49 & (94) & 28 & (97) & \multirow[t]{2}{*}{1.000} \\
\hline Recurrence & 4 & $(5)$ & 3 & $(6)$ & 1 & (3) & \\
\hline BM maximum diameter (mm, median [range]) & \multicolumn{2}{|c|}{$10[1-40]$} & \multicolumn{2}{|c|}{$8[1-36]$} & \multicolumn{2}{|c|}{$10[2-40]$} & 0.093 \\
\hline \multicolumn{8}{|l|}{ Number of BMs } \\
\hline Solitary & 12 & $(15)$ & 7 & (13) & 5 & $(17)$ & \multirow[t]{2}{*}{0.747} \\
\hline Multiple & 69 & $(85)$ & 45 & (87) & 24 & (83) & \\
\hline \multicolumn{8}{|l|}{ Symptom } \\
\hline Asymptomatic & 58 & $(72)$ & 35 & 67 & 23 & (79) & \multirow[t]{2}{*}{0.310} \\
\hline Symptomatic & 23 & (28) & 17 & 33 & 6 & (21) & \\
\hline Upfront CRT & & & & & & & \\
\hline No & 51 & (63) & 28 & (54) & 23 & (79) & 0.031 \\
\hline Yes & 30 & (37) & 24 & (46) & 6 & (21) & \\
\hline WBRT & 15 & (19) & 12 & (23) & 3 & (10) & \\
\hline SRT & 13 & (16) & 2 & (2) & 1 & (4) & \\
\hline WBRT+SRT & 2 & (2) & 1 & (21) & 2 & (7) & \\
\hline
\end{tabular}

PS: Eastern Cooperative Oncology Group performance status, BM: brain metastasis, Adeno: adenocarcinoma, EGFR mut: EGFR mutations, CRT: cranial radiotherapy, WBRT: Whole brain radiation therapy, SRT: Stereotactic radiotherapy.

shown to be higher compared to EGFR-wild type (35.3$38.1 \%)$ at the time of diagnosis $(10,11)$. EGFR-TKIs, such as gefitinib and erlotinib, display antitumor activity to BM in $E G F R$-mutant NSCLC patients (12). Moreover, a recent meta-analysis showed that upfront cranial radiotherapy (CRT) improved survival compared to EGFR-TKIs alone in EGFR-mutant NSCLC patients with BM (13). Despite these facts, the optimal treatment strategy, including the selection of EGFR-TKIs and the timing of CRT for EGFR-mutant NSCLC patients with BM, has not yet been fully determined.

For this reason, we performed a multicenter retrospective analysis to consider the optimal initial treatment strategy for EGFR-TKI selection and the timing of CRT for EGFRmutant NSCLC patients with BM in real-world clinical practice.

\section{Patients and Methods}

Study design and patient selection. We reviewed 86 consecutive patients with advanced or recurrent NSCLC harboring EGFR mutations who were treated with EGFR-TKIs as a first-line treatment between January 2010 and March 2016 at the Kumamoto University Hospital and six other community hospitals (Saiseikai Kumamoto Hospital, Kumamoto Red Cross Hospital, NHO Kumamoto Saishunso Hospital, Kumamoto Chuo Hospital, Kumamoto Rosai Hospital, and Kumamoto Regional Medical Center). Five patients were excluded because of uncommon $E G F R$ mutations $(\mathrm{G} 719 \mathrm{X}, \mathrm{n}=4$; L861Q, $\mathrm{n}=1)$. The remaining 81 patients were included in this study.

The following characteristics were collected at the initiation of EGFR-TKIs: i) age, ii) gender, iii) smoking status, iv) Eastern Cooperative Oncology Group performance status (PS), v) histology, vi) $E G F R$ mutation status, vii) stage, viii) diameter, ix) number, $\mathrm{x}$ ) 
Table II. Overall response to EGFR-TKIs according to the RECIST criteria.

\begin{tabular}{|c|c|c|c|c|c|c|c|}
\hline & \multicolumn{6}{|c|}{ Overall response } & \multirow[b]{3}{*}{$p$-Value } \\
\hline & \multicolumn{2}{|c|}{ All patients } & \multicolumn{2}{|c|}{ Gefitinib } & \multicolumn{2}{|c|}{ Erlotinib } & \\
\hline & $\mathrm{N}=81$ & $(\%)$ & $\mathrm{N}=52$ & $(\%)$ & $\mathrm{N}=29$ & $(\%)$ & \\
\hline CR & 0 & (0) & 0 & (0) & 0 & $(0)$ & \\
\hline PR & 62 & (77) & 37 & (71) & 25 & (86) & \\
\hline SD & 10 & (12) & 7 & (13) & 3 & (10) & \\
\hline PD & 5 & (6) & 4 & (8) & 1 & (3) & \\
\hline $\mathrm{NE}$ & 4 & (5) & 4 & (8) & 0 & (0) & \\
\hline $\begin{array}{l}\text { ORR, \% } \\
(95 \% \text { CI })\end{array}$ & \multicolumn{2}{|c|}{$\begin{array}{c}77 \\
(66-84)\end{array}$} & \multicolumn{2}{|c|}{$\begin{array}{c}71 \\
(58-82)\end{array}$} & \multicolumn{2}{|c|}{$\begin{array}{c}86 \\
(69-95)\end{array}$} & 0.174 \\
\hline
\end{tabular}

CR: complete response, PR: partial response, SD: stable disease, PD: progressive disease, NE: not evaluable, ORR: overall response rate, $\mathrm{CI}$ : confidence interval.

Table III. Intracranial response to EGFR-TKIs according to the RECIST criteria.

\begin{tabular}{|c|c|c|c|c|c|c|c|}
\hline & \multicolumn{6}{|c|}{ Intracranial response } & \multirow[b]{3}{*}{$p$-Value } \\
\hline & \multicolumn{2}{|c|}{ All patients } & \multicolumn{2}{|c|}{ Gefitinib } & \multicolumn{2}{|c|}{ Erlotinib } & \\
\hline & $\mathrm{N}=36$ & $(\%)$ & $\mathrm{N}=25$ & $\%$ & $\mathrm{~N}=11$ & $\%$ & \\
\hline CR & 3 & (8) & 2 & (8) & 1 & (9) & \\
\hline PR & 27 & (75) & 17 & (68) & 10 & (91) & \\
\hline SD & 3 & (8) & 3 & (12) & 0 & (0) & \\
\hline PD & 3 & (8) & 3 & (12) & 0 & (0) & \\
\hline $\mathrm{NE}$ & 0 & (0) & 0 & $(0)$ & 0 & $(0)$ & \\
\hline $\begin{array}{l}\text { ORR, \% } \\
(95 \% \mathrm{CI})\end{array}$ & \multicolumn{2}{|c|}{$\begin{array}{c}83 \\
(68-92)\end{array}$} & \multicolumn{2}{|c|}{$\begin{array}{c}84 \\
(57-88)\end{array}$} & \multicolumn{2}{|c|}{$\begin{array}{c}100 \\
(74-100)\end{array}$} & 0.290 \\
\hline
\end{tabular}

CR: complete response, PR: partial response, SD: stable disease, PD: progressive disease, NE: not evaluable, ORR: overall response rate, CI: confidence interval.

symptoms of BMs, xi) CRT for BM, xii) treatments, and xiii) adverse events. The clinical stage was classified according to the seventh edition of the TNM classification. EGFR mutations were detected using either the Cycleave, PCR-Invader, or PNA-LNA PCR Clamp methods. This study was approved by our institutional review board (IRB number: 1403).

Outcome parameters. The radiographic response was defined according to the Response Evaluation Criteria in Solid Tumors (RECIST) version 1.1. The objective response rate (ORR) was defined as the proportion of patients with a complete or a partial response, based on the best objective response. In cases with measurable intracranial lesions, the radiographic response of the intracranial tumors was assessed using the RECIST version 1.1, by comparing the pre- and post-treatment intracranial images.

Progression-free survival (PFS) was defined as the time from the initiation of EGFR-TKI administration to disease progression or death or last follow-up. Overall survival (OS) was defined as the time from the initiation of EGFR-TKIs to death or last follow-up. The adverse events were assessed using the Common Terminology Criteria for Adverse Events (CTCAE), version 4.0.

Statistical analysis. This is an observational cross-sectional study. Fisher's exact test was used to compare the association of clinical factors as categorical variables. The Mann-Whitney $U$-test was used for the continuous variables. Surviva1 curves of PFS or OS were estimated using the Kaplan-Meier method and were compared using the log-rank test. Multivariate analyses were performed using the Cox proportional hazards model. Covariate selection was finally determined according to backward stepwise regression, based on the Akaike's information criterion and following discussion with the clinicians. Schoenfeld residuals were assessed to evaluate the proportional hazards in these models. The statistical analyses were conducted using the JMP software, version 10, and the R software, version 3.3.2 (The R Foundation for Statistical Computing, Vienna, Austria). Values of $p<0.05$ were considered significant.

\section{Results}

Patient characteristics. The patients' characteristics are summarized in Table I. The median age at initiation of EGFRTKI administration was 68 years (range: 37-89 years). Additionally, 23 (28\%) patients were male, 24 (30\%) were smokers, $58(72 \%)$ had PS stage 0 or $1,79(98 \%)$ had adenocarcinoma, and $77(95 \%)$ were stage IV at the time of treatment (Table I). In total, $41 \%$ of patients displayed the exon 19 deletion (Del19), and 59\% of patients displayed the singlepoint substitution mutation L858R in exon 21 (L858R). The median maximum diameter of the BMs was $10 \mathrm{~mm}$. The proportion of symptomatic BMs and upfront CRT was $17 \%$ and 9\%, respectively. Among the patients with upfront CRT, 15 patients (19\%) received WBRT, $13(16 \%)$ received stereotactic radiotherapy (SRT), and $2(2 \%)$ received both WBRT and SRT.

Among the 81 patients, 52 received $250 \mathrm{mg}$ /day of gefitinib and 29 received $150 \mathrm{mg}$ /day of erlotinib. There were no significant differences in baseline characteristics between the gefitinib and erlotinib groups except for a lower percentage of upfront CRT in the erlotinib group (21\% vs. $46 \%$, respectively, $p=0.031$ ).

Response. The ORR was $77 \%$ (95\% confidence interval [CI]: 66-84) in all patients (Table II). The ORR was higher in the erlotinib group than in the gefitinib group, but this difference was not significant (86\% [95\% CI: 69-95\%] vs. $71 \%$ [95\% CI: $58-82 \%$ ], $p=0.174)$.

Thirty-six patients had intracranial measurable lesions and were evaluated by radiographic examinations during the EGFR-TKI treatment. The intracranial response rate was $83 \%$ (95\% CI: 68-92\%) in all patients (Table III). The intracranial response in the erlotinib group was higher compared to the gefitinib group, but the difference was not significant (100\% [95\% CI: 74-100\%] vs. $84 \%$ [95\% CI: $57-$ $88 \%$ ], $p=0.290)$. 

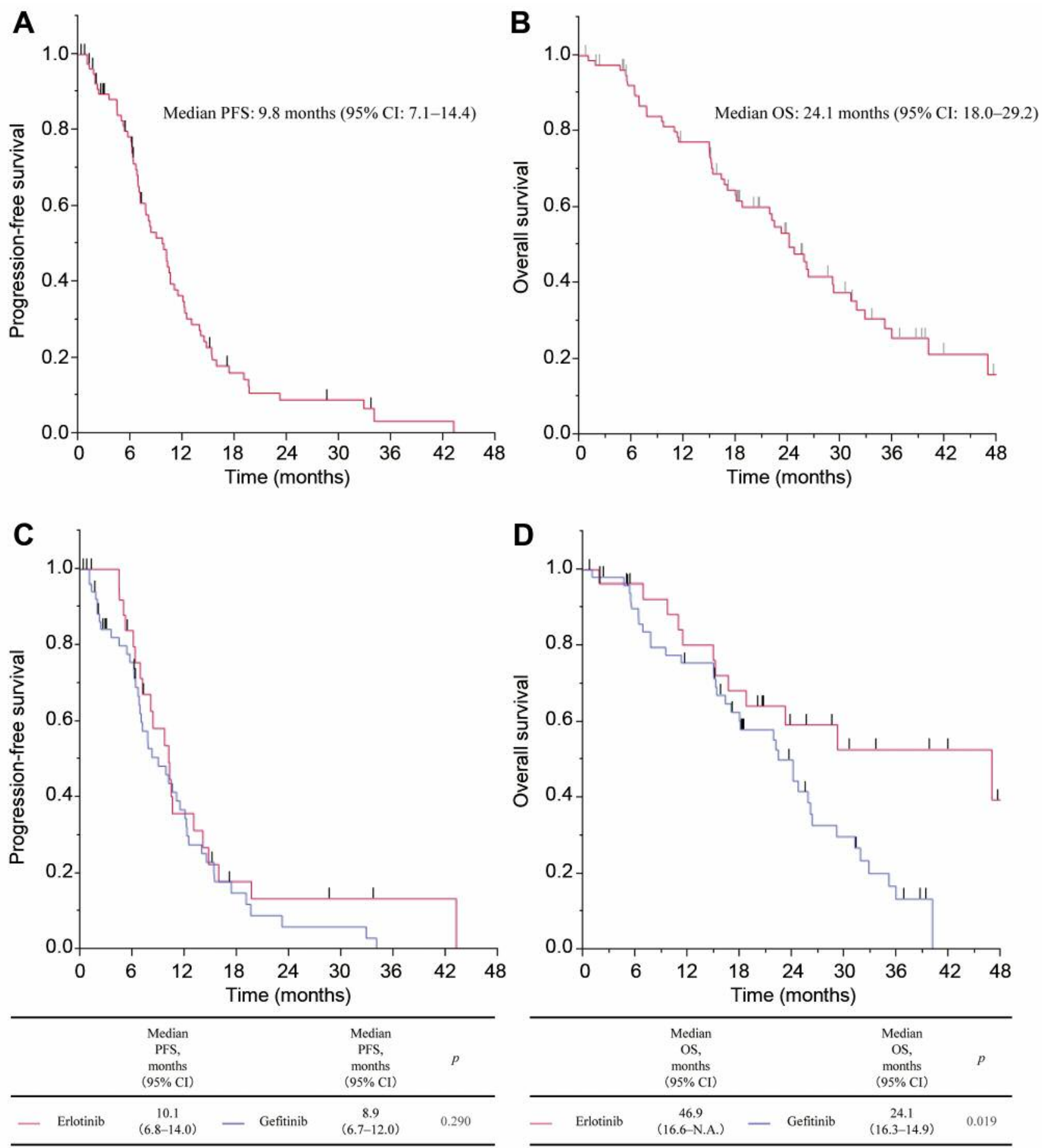

Figure 1. Kaplan-Meier survival curves for PFS and OS. PFS (A) and OS (B) in all patients. PFS (C) and OS (D) are according to the EGFR-TKIs administered.

PFS and OS. The median follow-up from the initiation of EGFR-TKI administration was 18.2 months (range 0.6-49.8 months). The median PFS and OS in all patients was 9.8 (95\% CI: 7.1-14.4) and 24.1 months (95\% CI: 18.0-29.2), respectively (Figure 1A and B). The median PFS in the erlotinib group was longer compared to the gefitinib group, but the difference was not significant $(10.1$ [95\% CI: 6.814.0] vs. 8.9 [95\% CI: 6.7-12.0] months, $p=0.290$ ) (Figure 

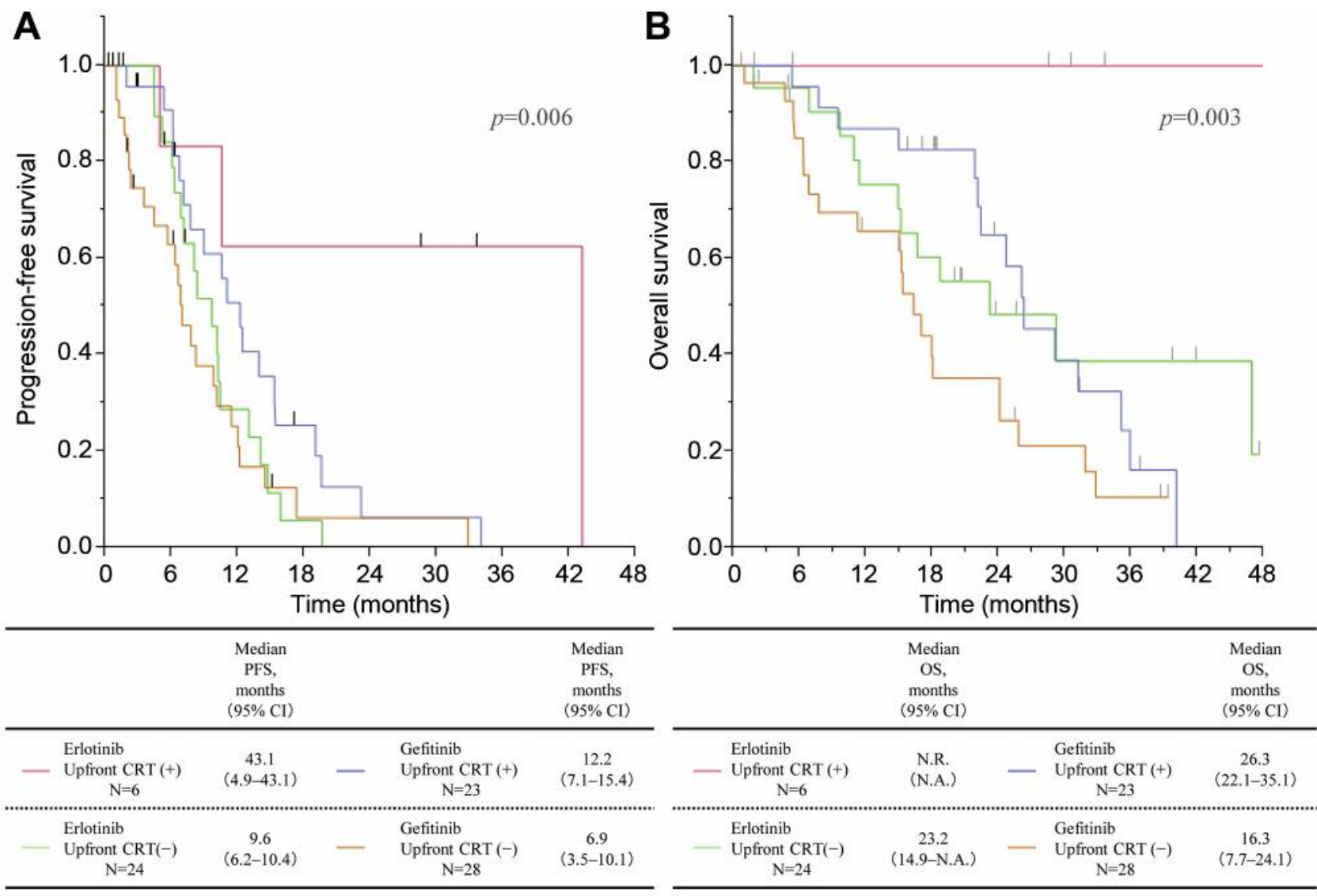

N.R.: not reached, N.A.: not available

Figure 2. Kaplan-Meier survival curves for PFS (A) and OS (B) according to EGFR-TKIS and upfront CRT.

Table IV. Initial progression site and subsequent chemotherapy.

\begin{tabular}{|c|c|c|c|c|c|c|c|}
\hline & \multicolumn{2}{|c|}{ All patients } & \multicolumn{2}{|c|}{ Gefitinib } & \multicolumn{2}{|c|}{ Erlotinib } & \multirow[t]{2}{*}{$p$-Value } \\
\hline & $\mathrm{N}$ & $(\%)$ & $\mathrm{N}$ & $(\%)$ & $\mathrm{N}$ & $(\%)$ & \\
\hline Intracranial progression & 21 & (26) & 17 & (33) & 4 & (14) & 0.071 \\
\hline \multicolumn{8}{|l|}{ Extracranial progression } \\
\hline Intrathoracic & 28 & (35) & 18 & (35) & 10 & (35) & 1.000 \\
\hline Pleural effusion/dissemination & 10 & (12) & 6 & (12) & 4 & (14) & 0.740 \\
\hline Liver & 8 & (10) & 5 & (10) & 3 & (10) & 1.000 \\
\hline Bone & 9 & (11) & 5 & (10) & 4 & (14) & 0.715 \\
\hline Adrenal & 2 & (2) & 2 & (4) & 0 & $(0)$ & 0.535 \\
\hline Second-line therapy & 52 & (64) & 20 & (69) & 32 & (61) & 0.630 \\
\hline Use of osimertinib & 7 & (9) & 1 & (2) & 6 & (21) & 0.008 \\
\hline
\end{tabular}

1C). Interestingly, the median OS in the erlotinib group was significantly longer compared to the gefitinib group (46.9 [95\% CI: 16.6-N.A.] vs. 24.1 [95\% CI: 16.3-26.3] months, $p=0.019)$ (Figure 1D).
Initial progression pattern and subsequent therapy. Table IV displays the recurrence patterns and subsequent chemotherapy. The initial progression pattern was assessed as follows: 21 patients (26\%) had central nervous system (CNS) progression, 
$28(35 \%)$ had intrathoracic lesions, $10(12 \%)$ had pleural effusion/dissemination, 8 (10\%) had bone progression, and 2 (2\%) had adrenal metastasis. Although there were no significant differences in extracranial progressions among the erlotinib and gefitinib groups, the CNS progression rate tended to be lower in the erlotinib group compared to the gefitinib group (14\% vs. 33\%, $p=0.071)$.

Fifty-two patients (64\%) received subsequent therapy, however, there were no significant differences between the patients who received subsequent therapy in the gefitinib and erlotinib groups. Interestingly, the percentage of patients who subsequently received osimertinib following confirmation of disease progression in the erlotinib group was significantly higher compared to the gefitinib group $(21 \%$ vs. $2 \%, p=0.008)$.

Multivariate analysis for PFS and OS. The multivariate analysis for PFS showed that the BM maximum diameter, use of erlotinib, and upfront CRT were significantly associated with prolonging PFS (erlotinib: hazard ratio [HR], $0.47 ; 95 \%$ confidence interval $[\mathrm{CI}], 0.26-0.84 ; p=0.011$; upfront CRT: HR, 0.38; 95\% CI, 0.19-0.77; $p=0.009$, Table $\mathrm{V})$. The multivariate analysis for OS showed that age $<70$, PS0-1, symptomatic BM, use of erlotinib, and upfront CRT were significantly associated with the prolongation of OS (erlotinib: HR, 0.21; 95\% CI, 0.10-0.48; $p<0.001$; upfront CRT: HR, 0.42; 95\% CI, 0.20-0.88; $p=0.022$, Table VI).

We performed further analyses by dividing the patients into four groups, according to EGFR-TKIs and upfront CRT. The PFS and OS curves for each group are shown in Figure $2 \mathrm{~A}$ and $\mathrm{B}$. The median PFS of the patients treated with erlotinib and upfront CRT, erlotinib without upfront CRT, gefitinib and upfront CRT, and gefitinib without upfront CRT was $43.1,9.6,12.2$, and 6.9 months, respectively $(p=0.006)$. The median OS of the patients treated with erlotinib and upfront CRT was not reached, whereas patients treated with erlotinib without upfront CRT, gefitinib and upfront CRT, and gefitinib without upfront CRT had OS of 23.2,26.3, and 16.3 months, respectively $(p=0.003)$.

Adverse events. Table VII shows the adverse events that occurred in the gefitinib and erlotinib groups. There was a tendency for a higher proportion of skin rash, paronychia, and oral mucositis in the erlotinib group compared to the gefitinib group (rash: $83 \%$ vs $67 \%$, paronychia: $14 \%$ vs. $4 \%$, and oral mucositis: $14 \%$ vs. $2 \%$ ). Additionally, there was significantly less liver dysfunction in the erlotinib group than in the gefitinib group $(21 \% v s .48 \%, p=0.018)$. The frequency of grade $\geq 3$ adverse events was low in both groups.

\section{Discussion}

We conducted a multicenter retrospective study to consider the optimal strategy for advanced/recurrent EGFR-mutant
Table V. Multivariate analysis for progression-free survival (PFS).

\begin{tabular}{lcc}
\hline Variables & HR $(95 \% \mathrm{CI})$ & $p$-Value \\
\hline Smoking history & 1 & \\
$\quad$ No & $1.63(0.94-2.81)$ & 0.081 \\
$\quad$ Yes & 1 & \\
BM maximum diameter & $1.96(1.09-3.53)$ & 0.025 \\
$\quad<10 \mathrm{~mm}$ & 1 & \\
$\quad \geq 10 \mathrm{~mm}$ & $0.54(0.26-1.16)$ & \\
Symptom & 1 & \\
$\quad$ Asymptomatic & & 0.115 \\
$\quad$ Symptomatic & $0.47(0.26-0.84)$ & \\
EGFR-TKI & & \\
$\quad$ Gefitinib & 1 & 0.011 \\
Erlotinib & $0.38(0.19-0.77)$ & \\
Upfront CRT & & \\
$\quad$ No & & \\
$\quad$ Yes &
\end{tabular}

PS: Eastern Cooperative Oncology Group performance status, BM: brain metastasis, CRT: cranial radiotherapy.

Table VI. Multivariate analysis for overall survival (OS).

\begin{tabular}{|c|c|c|}
\hline Variables & HR $(95 \% \mathrm{CI})$ & $p$-Value \\
\hline \multicolumn{3}{|l|}{ Age } \\
\hline$<70$ & 1 & 0.011 \\
\hline$\geq 70$ & $2.44(1.23-4.85)$ & \\
\hline \multicolumn{3}{|l|}{ Smoking history } \\
\hline No & 1 & 0.126 \\
\hline Yes & $1.76(0.85-3.64)$ & \\
\hline \multicolumn{3}{|l|}{ PS } \\
\hline $0-1$ & 1 & 0.003 \\
\hline$\geq 2$ & $3.09(1.47-6.52)$ & \\
\hline \multicolumn{3}{|l|}{ Symptom } \\
\hline Asymptomatic & 1 & 0.041 \\
\hline Symptomatic & $0.41(0.18-0.96)$ & \\
\hline \multicolumn{3}{|l|}{ EGFR-TKI } \\
\hline Gefitinib & 1 & $<0.001$ \\
\hline Erlotinib & $0.21(0.10-0.48)$ & \\
\hline \multicolumn{3}{|l|}{ Upfront CRT } \\
\hline No & 1 & 0.022 \\
\hline Yes & $0.42(0.20-0.88)$ & \\
\hline
\end{tabular}

PS: Eastern Cooperative Oncology Group performance status, BM: brain metastasis, CRT: cranial radiotherapy.

NSCLC patients with BM as the initial treatment. We found that upfront CRT followed by erlotinib improved PFS and OS compared to other treatment strategies in EGFR-mutant NSCLC patients.

Several randomized phase III studies of first-generation EGFR-TKIs (gefitinib or erlotinib) in treatment-naïve advanced EGFR-mutant NSCLC patients showed that the ORR, PFS, and OS were 58.1-83\%, 9.2-13.1 months, and 19.3-30.9 months, respectively (6-9). Several previous 


\begin{tabular}{|c|c|c|c|c|c|c|c|c|c|}
\hline & \multicolumn{4}{|c|}{ Gefitinib } & \multicolumn{4}{|c|}{ Erlotinib } & \multirow[b]{3}{*}{$p$ for all grad } \\
\hline & \multicolumn{2}{|c|}{ All grade } & \multicolumn{2}{|c|}{ Grade $\geq 3$} & \multicolumn{2}{|c|}{ All grade } & \multicolumn{2}{|c|}{ Grade $\geq 3$} & \\
\hline & $\mathrm{N}$ & $(\%)$ & $\mathrm{N}$ & $(\%)$ & $\mathrm{N}$ & $(\%)$ & $\mathrm{N}$ & $\%$ & \\
\hline Rash & 35 & (67) & 1 & (2) & 24 & $(83)$ & 2 & (7) & 0.193 \\
\hline Paronychia & 2 & (4) & 0 & $(0)$ & 4 & (14) & 0 & $(0)$ & 0.180 \\
\hline Oral mucositis & 1 & (2) & 0 & $(0)$ & 4 & (14) & 0 & (0) & 0.053 \\
\hline Nausea/Appetite loss & 14 & (26) & 0 & (0) & 7 & (24) & 2 & (7) & 1.000 \\
\hline Diarrhea & 14 & (27) & 0 & (0) & 12 & (41) & 3 & (10) & 0.219 \\
\hline AST/ALT elevated & 25 & (48) & 8 & (15) & 6 & (21) & 1 & (3) & 0.018 \\
\hline Interstitial pneumonia & 2 & (4) & 1 & (2) & 2 & (7) & 1 & (3) & 1.000 \\
\hline
\end{tabular}

studies of first-generation EGFR-TKIs for EGFR-mutant NSCLC patients with BM showed that the ORR, PFS, and OS were 75-83\%, 6.6-15.2 months, and 15.9-37.5 months, respectively $(14,15)$. In the present study, the ORR, PFS, and OS of EGFR-mutant NSCLC patients with BM were $77 \%, 9.8$ months, and 24.1 months, respectively, which are consistent with previous reports. Considering that the survival of NSCLC patients with BM who are treated with chemotherapy and radiotherapy was appropriately six months, EGFR-TKIs are notably effective for EGFR-mutant NSCLC patients with BM.

In the present study, the multivariate analysis showed that erlotinib significantly improved OS compared to gefitinib in $E G F R$-mutant NSCLC patients with BM. Randomized phase III studies comparing erlotinib with gefitinib in EGFRmutant NSCLC patients have shown that erlotinib was not significantly superior to gefitinib in terms of survival, which is inconsistent with our results $(16,17)$. This difference may be explained as a result of our limited study sample of EGFR-mutant NSCLC patients with BM. Two factors may account for the survival benefit provided by erlotinib in EGFR-mutant NSCLC patients with BM. First, erlotinib displayed better CNS management (slightly higher intracranial response and less CNS progression) compared to gefitinib. Togashi et al. showed that the cerebrospinal fluid concentration and penetration rate of erlotinib may be higher compared to gefitinib, which can contribute to a more effective treatment of CNS metastases (18). Moreover, the approved clinical dose of erlotinib (150 mg/day) is the maximum dose tolerated, whereas the approved dose of gefitinib (250 mg/day) is approximately one-third of the maximum dose tolerated in Japan. Since the serum concentration of erlotinib in clinical settings can be higher compared to gefitinib, this may act as an advantage of this therapeutic, resulting in better management of CNS metastases, especially given the difficulty of identifying drugs that penetrate the blood-brain barrier (BBB) (19). In addition, the usage rate of subsequent osimertinib in the erlotinib group was higher compared to the gefitinib group. Osimertinib demonstrates a high clinical efficacy in patients with advanced NSCLC diagnosed with T790M resistance mutation, and re-biopsy for T790M detection is needed after disease progression on initial EGFR-TKI therapy (20). Given that re-biopsy for determining candidates of osimertinib may be difficult in cases with only CNS metastases and deteriorating PS leading to BM, erlotinib may provide an opportunity for conducting a re-biopsy to detect T790M. Moreover, osimertinib may prevent the progression of BM to a greater degree than gefitinib. Based on these findings, erlotinib treatment may result in a better management of BM and consequently contribute to prolong the survival of this population.

Our multivariate analysis showed that upfront CRT was associated with improvement in both PFS and OS in EGFRmutant NSCLC patients with BM. Magnuson et al. have described that upfront stereotactic radiosurgery and WBRT significantly prolong OS and present with a lower probability of intracranial progression compared to upfront EGFR-TKIs in EGFR-mutant NSCLC patients with BM (median OS: 46, 30, and 25 months, respectively, $p<0.001$; median time to intracranial progression: 23,24 , and 17 months, respectively, $p=0.025$ ) (21). A meta-analysis by Soon et al. has shown that upfront CRT significantly improve intracranial PFS and OS in EGFR-mutant NSCLC patients with BM compared to EGFRTKI alone (13). Our results are consistent with these previous reports. Several explanations have been proposed for the survival benefit of upfront CRT. First, the CNS is frequently the initial progression site following EGFR-TKI treatment, thus, better intracranial management of upfront CRT would improve both PFS and OS (22). Second, there is heterogeneity in the EGFR mutations between BMs and primary/other metastatic sites. Gow et al. has identified a discordance in the EGFR mutations 
between the primary site and the corresponding BM in 8 of 12 patients $(75 \%)$ via a direct nucleotide sequencing analysis, and in 4 of 8 patients $(50 \%)$, based on the Scorpion Amplified Refractory Mutation System assay (23). Consequently, EGFRTKIs alone are insufficient for the management of BM in EGFRmutant NSCLC patients with BM. Third, radiotherapy can disrupt the BBB, and increased permeability of the BBB can hamper the efficacy of the chemotherapeutic agent for intracranial tumors (24). Because the CSF penetration rate of EGFR-TKIs is extremely low (1.1-2.8\%), upfront CRT might enhance the antitumor effect of EGFR-TKIs on intracranial lesions by changing the BBB permeability to EGFR-TKIs (18).

The toxicity profiles were also assessed. There was a tendency for a higher frequency of skin rash, paronychia, and oral mucositis in the erlotinib group, while there was a significantly higher frequency of liver dysfunctions in the gefitinib group compared to the erlotinib group. Togashi et al. showed that in Japanese patients with NSCLC, a higher frequency of adverse events, including skin rash, diarrhea, oral mucositis, and gastrointestinal toxicity, occurred in the erlotinib group compared to the gefitinib group (25). Moreover, Takeda et al. showed that gefitinib is associated with higher hepatotoxicity compared to erlotinib (26). Our results are similar to these previous reports. Despite the different toxicity profiles between gefitinib and erlotinib, the serious adverse event rate was mild and manageable using either drug.

Our study had several limitations. First, our analysis was based on a retrospective and relatively small patient sample size. Second, the choice of EGFR-TKI and the timing of CRT depended on the physician, so a bias in treatment selection might be present. Third, this study did not include patients who received second- and third-generation drugs, such as afatinib, dacomitinib, and osimertinib, as initial treatments. Recently, these EGFR-TKIs have shown a higher clinical efficacy compared to first-generation EGFR-TKIs (gefitinib or erlotinib) in NSCLC patients with EGFR mutations (27-29). Thus, our results should be interpreted cautiously, and larger prospective studies including second- and third-generation EGFR-TKIs must be conducted to confirm these findings.

The current study showed that erlotinib and upfront CRT prolonged OS compared to gefitinib and no upfront CRT in EGFR-mutant NSCLC patients with BM. Upfront CRT followed by erlotinib might be an appropriate initial treatment management approach for EGFR-mutant NSCLC patients with BM.

\section{Conflicts of Interest}

The Authors have no conflicts of interest to disclose.

\section{Funding}

This study was supported by Novartis Pharma K.K.

\section{Acknowledgements}

The Authors are grateful to Ms. Miyuki Tashiro and Ms. Yuka Tamura for their support in this study.

\section{References}

1 Schouten LJ, Rutten J, Huveneers HA and Twijnstra A: Incidence of brain metastases in a cohort of patients with carcinoma of the breast, colon, kidney, and lung and melanoma. Cancer 94(10): 2698-2705, 2002.

2 Owonikoko TK, Arbiser J, Zelnak A, Shu HK, Shim H, Robin AM, Kalkanis SN, Whitsett TG, Salhia B, Tran NL, Ryken T, Moore MK, Egan KM and Olson JJ: Current approaches to the treatment of metastatic brain tumours. Nat Rev Clin Oncol 11(4): 203-222, 2014.

3 Peters S, Bexelius C, Munk V and Leighl N: The impact of brain metastasis on quality of life, resource utilization and survival in patients with non-small-cell lung cancer. Cancer Treat Rev 45: 139-162, 2016.

4 Lynch TJ, Bell DW, Sordella R, Gurubhagavatula S, Okimoto RA, Brannigan BW, Harris PL, Haserlat SM, Supko JG, Haluska FG, Louis DN, Christiani DC, Settleman J and Haber DA: Activating mutations in the epidermal growth factor receptor underlying responsiveness of non-small-cell lung cancer to gefitinib. N Engl J Med 350(21): 2129-2139, 2004.

5 Paez JG, Janne PA, Lee JC, Tracy S, Greulich H, Gabriel S, Herman P, Kaye FJ, Lindeman N, Boggon TJ, Naoki K, Sasaki H, Fujii Y, Eck MJ, Sellers WR, Johnson BE and Meyerson M: Egfr mutations in lung cancer: Correlation with clinical response to gefitinib therapy. Science 304(5676): 1497-1500, 2004.

6 Mitsudomi T, Morita S, Yatabe Y, Negoro S, Okamoto I, Tsurutani J, Seto T, Satouchi M, Tada H, Hirashima T, Asami K, Katakami N, Takada M, Yoshioka H, Shibata K, Kudoh S, Shimizu E, Saito H, Toyooka S, Nakagawa K and Fukuoka M: Gefitinib versus cisplatin plus docetaxel in patients with nonsmall-cell lung cancer harbouring mutations of the epidermal growth factor receptor (wjtog3405): An open label, randomised phase 3 trial. Lancet Oncol 11(2): 121-128, 2010.

7 Rosell R, Carcereny E, Gervais R, Vergnenegre A, Massuti B, Felip E, Palmero R, Garcia-Gomez R, Pallares C, Sanchez JM, Porta R, Cobo M, Garrido P, Longo F, Moran T, Insa A, De Marinis F, Corre R, Bover I, Illiano A, Dansin E, de Castro J, Milella M, Reguart N, Altavilla G, Jimenez U, Provencio M, Moreno MA, Terrasa J, Munoz-Langa J, Valdivia J, Isla D, Domine M, Molinier O, Mazieres J, Baize N, Garcia-Campelo R, Robinet G, RodriguezAbreu D, Lopez-Vivanco G, Gebbia V, Ferrera-Delgado L, Bombaron P, Bernabe R, Bearz A, Artal A, Cortesi E, Rolfo C, Sanchez-Ronco M, Drozdowskyj A, Queralt C, de Aguirre I, Ramirez JL, Sanchez JJ, Molina MA, Taron M and Paz-Ares L: Erlotinib versus standard chemotherapy as first-line treatment for european patients with advanced egfr mutation-positive non-smallcell lung cancer (eurtac): A multicentre, open-label, randomised phase 3 trial. Lancet Oncol 13(3): 239-246, 2012.

8 Zhou C, Wu YL, Chen G, Feng J, Liu XQ, Wang C, Zhang S, Wang J, Zhou S, Ren S, Lu S, Zhang L, Hu C, Hu C, Luo Y, Chen L, Ye M, Huang J, Zhi X, Zhang Y, Xiu Q, Ma J, Zhang L and You C: Erlotinib versus chemotherapy as first-line treatment for patients with advanced egfr mutation-positive non-small-cell lung cancer (optimal, ctong-0802): A multicentre, open-label, randomised, phase 3 study. Lancet Oncol 12(8): 735-742, 2011. 
9 Maemondo M, Inoue A, Kobayashi K, Sugawara S, Oizumi S Isobe $\mathrm{H}$, Gemma A, Harada M, Yoshizawa H, Kinoshita I, Fujita Y, Okinaga S, Hirano H, Yoshimori K, Harada T, Ogura T, Ando M, Miyazawa H, Tanaka T, Saijo Y, Hagiwara K, Morita S and Nukiwa T: Gefitinib or chemotherapy for nonsmall-cell lung cancer with mutated egfr. N Engl J Med 362(25): 2380-2388, 2010.

10 Ge M, Zhuang Y, Zhou X, Huang R, Liang X and Zhan Q: High probability and frequency of egfr mutations in non-small cell lung cancer with brain metastases. J Neurooncol 135(2): 413418, 2017.

11 Shin DY, Na, II, Kim CH, Park S, Baek H and Yang SH: Egfr mutation and brain metastasis in pulmonary adenocarcinomas. J Thorac Oncol 9(2): 195-199, 2014.

12 Fan Y, Xu X and Xie C: Egfr-tki therapy for patients with brain metastases from non-small-cell lung cancer: A pooled analysis of published data. Onco Targets Ther 7: 2075-2084, 2014.

13 Soon YY, Leong CN, Koh WY and Tham IW: Egfr tyrosine kinase inhibitors versus cranial radiation therapy for egfr mutant non-small cell lung cancer with brain metastases: A systematic review and meta-analysis. Radiother Oncol 114(2): 167-172, 2015.

14 Wu YL, Zhou C, Cheng Y, Lu S, Chen GY, Huang C, Huang YS, Yan HH, Ren S, Liu Y and Yang JJ: Erlotinib as second-line treatment in patients with advanced non-small-cell lung cancer and asymptomatic brain metastases: A phase ii study (ctong0803). Ann Oncol 24(4): 993-999, 2013.

15 Park SJ, Kim HT, Lee DH, Kim KP, Kim SW, Suh C and Lee JS: Efficacy of epidermal growth factor receptor tyrosine kinase inhibitors for brain metastasis in non-small cell lung cancer patients harboring either exon 19 or 21 mutation. Lung Cancer 77(3): 556-560, 2012.

16 Urata Y, Katakami N, Morita S, Kaji R, Yoshioka H, Seto T, Satouchi M, Iwamoto Y, Kanehara M, Fujimoto D, Ikeda N, Murakami H, Daga H, Oguri T, Goto I, Imamura F, Sugawara S, Saka H, Nogami N, Negoro S, Nakagawa K and Nakanishi Y: Randomized phase iii study comparing gefitinib with erlotinib in patients with previously treated advanced lung adenocarcinoma: Wjog 51081. J Clin Oncol 34(27): 3248-3257, 2016.

17 Yang JJ, Zhou Q, Yan HH, Zhang XC, Chen HJ, Tu HY, Wang Z, Xu CR, Su J, Wang BC, Jiang BY, Bai XY, Zhong WZ, Yang $\mathrm{XN}$ and $\mathrm{Wu}$ YL: A phase iii randomised controlled trial of erlotinib vs gefitinib in advanced non-small cell lung cancer with egfr mutations. Br J Cancer 116(5): 568-574, 2017.

18 Togashi Y, Masago K, Masuda S, Mizuno T, Fukudo M, Ikemi Y, Sakamori Y, Nagai H, Kim YH, Katsura T and Mishima M: Cerebrospinal fluid concentration of gefitinib and erlotinib in patients with non-small cell lung cancer. Cancer Chemother Pharmacol 70(3): 399-405, 2012.

19 Togashi Y, Hayashi H, Nakagawa K and Nishio K: Clinical utility of erlotinib for the treatment of non-small-cell lung cancer in japanese patients: Current evidence. Drug Des Devel Ther 8: 1037-1046, 2014.

20 Mok TS, Wu YL, Ahn MJ, Garassino MC, Kim HR, Ramalingam SS, Shepherd FA, He Y, Akamatsu H, Theelen WS, Lee CK, Sebastian M, Templeton A, Mann H, Marotti M, Ghiorghiu S and Papadimitrakopoulou VA: Osimertinib or platinum-pemetrexed in egfr t790m-positive lung cancer. N Engl J Med 376(7): 629-640, 2017.
21 The Lancet Oncology 2010 -M, W. J., Lester-Coll NH, Wu AJ, Yang TJ, Lockney NA, Gerber NK, Beal K, Amini A, Patil T, Kavanagh BD, Camidge DR, Braunstein SE, Boreta LC, Balasubramanian SK, Ahluwalia MS, Rana NG, Attia A, Gettinger SN, Contessa JN, Yu JB and Chiang VL: Management of brain metastases in tyrosine kinase inhibitor-naive epidermal growth factor receptor-mutant non-small-cell lung cancer: A retrospective multi-institutional analysis. J Clin Oncol 35(10): 1070-1077, 2017.

22 Lee YJ, Choi HJ, Kim SK, Chang J, Moon JW, Park IK, Kim $\mathrm{JH}$ and Cho BC: Frequent central nervous system failure after clinical benefit with epidermal growth factor receptor tyrosine kinase inhibitors in korean patients with nonsmall-cell lung cancer. Cancer 116(5): 1336-1343, 2010.

23 Gow CH, Chang YL, Hsu YC, Tsai MF, Wu CT, Yu CJ, Yang CH, Lee YC, Yang PC and Shih JY: Comparison of epidermal growth factor receptor mutations between primary and corresponding metastatic tumors in tyrosine kinase inhibitor-naive non-small-cell lung cancer. Ann Oncol 20(4): 696-702, 2009.

24 Van Vulpen M, Kal HB, Taphoorn MJ and El-Sharouni SY: Changes in blood-brain barrier permeability induced by radiotherapy: Implications for timing of chemotherapy? (review). Oncol Rep 9(4): 683-688, 2002.

25 Togashi Y, Masago K, Fujita S, Hatachi Y, Fukuhara A, Nagai H, Sakamori Y, Kim YH, Mio T and Mishima M: Differences in adverse events between $250 \mathrm{mg}$ daily gefitinib and $150 \mathrm{mg}$ daily erlotinib in japanese patients with non-small cell lung cancer. Lung Cancer 74(1): 98-102, 2011.

26 Takeda M, Okamoto I and Nakagawa K: Pooled safety analysis of egfr-tki treatment for egfr mutation-positive non-small cell lung cancer. Lung Cancer 88(1): 74-79, 2015.

27 Park K, Tan EH, O'Byrne K, Zhang L, Boyer M, Mok T, Hirsh V, Yang JC, Lee KH, Lu S, Shi Y, Kim SW, Laskin J, Kim DW, Arvis CD, Kolbeck K, Laurie SA, Tsai CM, Shahidi M, Kim M, Massey D, Zazulina V and Paz-Ares L: Afatinib versus gefitinib as first-line treatment of patients with egfr mutation-positive non-small-cell lung cancer (lux-lung 7): A phase 2b, open-label, randomised controlled trial. Lancet Oncol 17(5): 577-589, 2016.

28 Soria JC, Ohe Y, Vansteenkiste J, Reungwetwattana T, Chewaskulyong B, Lee KH, Dechaphunkul A, Imamura F, Nogami N, Kurata T, Okamoto I, Zhou C, Cho BC, Cheng Y, Cho EK, Voon PJ, Planchard D, Su WC, Gray JE, Lee SM, Hodge R, Marotti M, Rukazenkov $\mathrm{Y}$ and Ramalingam SS: Osimertinib in untreated egfr-mutated advanced non-small-cell lung cancer. N Engl J Med 378(2): 113-125, 2018.

29 Wu YL, Cheng Y, Zhou X, Lee KH, Nakagawa K, Niho S, Tsuji F, Linke R, Rosell R, Corral J, Migliorino MR, Pluzanski A, Sbar EI, Wang T, White JL, Nadanaciva S, Sandin R and Mok TS: Dacomitinib versus gefitinib as first-line treatment for patients with egfr-mutation-positive non-small-cell lung cancer (archer 1050): A randomised, open-label, phase 3 trial. Lancet Oncol 18(11): 1454-1466, 2017.

Received December 8, 2018

Revised January 7, 2019

Accepted January 17, 2019 